\title{
The effect of Quercus infectoria pair cream on the severity of episiotomy pain in nulliparous women
}

\author{
Roza Soltanifard $^{1 \oplus}$, Fatemeh Nahidi ${ }^{2^{*}}$, Faraz Mojab $^{3 \oplus}$, Mehdi Birjandi $^{4^{\circledR}}$ \\ ${ }^{1}$ Department of Midwifery and Reproductive Health, Shahid Beheshti University of Medical Sciences, Tehran, Islamic Republic of Iran \\ ${ }^{2} \mathrm{PhD}$ of Health Education, Associate Professor of Department of Midwifery \& Reproductive Health, Shahid Beheshti University of Medical Sciences, \\ Tehran, Islamic Republic of Iran \\ ${ }^{3}$ School of Pharmacy, Shahid Beheshti University of Medical Sciences, Tehran, Iran \\ ${ }^{4}$ Department of Biostatistics and Epidemiology, School of Health and Nutrition, Lorestan University of Medical Sciences, Khorramabad, Iran
}

\section{A R T I C L E I N F O}

\section{Article Type:}

Original Article

\section{Article History:}

Received: 20 October 2020

Accepted: 31 December 2020

\section{Keywords:}

Episiotomy

Nulliparous women

Quercus infectoria

Pain

\begin{abstract}
A B S T R A C T
Introduction: Episiotomy is an incision in the perineal area during the second stage of labor to facilitate delivery. Complications of perineal injuries are one of the most important health issues. Oak pair has long been used experimentally to heal wounds and reduce pain. The present study was performed to investigate the effect of oak pair (Quercus infectoria) cream on pain due to episiotomy in nulliparous women.

Methods: This double-blind clinical trial experimental study was performed on 120 nulliparous women in Asali hospital in 2018. Individuals were randomly divided into oak pair cream, placebo, and normal saline groups. Data were collected by demographic and midwifery information questionnaires and numerical pain scales. The creams were used by the participants every 12 hours for 10 days, and the pain intensity was evaluated before the intervention and on days 1, 5, and 10. Data analysis was performed by SPSS using chi-square, Kruskal-Wallis, and one-way analysis of variance (ANOVA) tests.

Results: There was no statistically significant difference in pain intensity scores among the three groups of oak pair, placebo, and normal saline before the intervention $(P=0.20)$. Pain intensity on days 1,5 , and 10 after the intervention showed a significant difference between the three groups in favor of oak cream $(P<0.001)$. The results showed that there was a significant decrease in the mean pain intensity score of the oak pair receiving group over time $(P<0.001)$. Conclusion: Oak cream might be effective in reducing pain caused by episiotomy due to analgesic properties.
\end{abstract}

Implication for health policy/practice/research/medical education:

Methanol extract of Quercus infectoria pair reduces episiotomy pain in nulliparous women activity and might be used as episiotomy pain therapy for prevention of nulliparous women mainly caused by drugs.

Please cite this paper as: Soltanifard R, Nahidi F, Mojab F, Birjandi M. The effect of Quercus infectoria pair cream on the severity of episiotomy pain in nulliparous women. J Herbmed Pharmacol. 2021;10(4):401-407. doi: 10.34172/jhp.2021.47.

\section{Introduction}

Episiotomy is a surgical incision in the perineal area that helps facilitate the birth of a baby by enlarging the vaginal entrance during the second stage of labor (1), and is one of the most common midwifery interventions (2). The World Health Organization recommends a 10\% prevalence for episiotomy operations (3). In line with this trend, the prevalence of episiotomy decreased from $60.9 \%$ to $24.5 \%$ in the United States between 1979 and 2004. (4). The prevalence of episiotomy varies from 9.7\% in Sweden to about $100 \%$ in Taiwan (5). In Asian women, due to their short and rigid perineal structure, they are at higher risk for injuries to the lower part of the area during childbirth (6), so that the prevalence of episiotomy in Oman and Saudi Arabia is $66 \%$ and 20\%, respectively (7). Although it is not possible to access accurate statistics on the prevalence of episiotomy in Iran, high birth rates can raise the possibility of a high prevalence of episiotomy. The prevalence of episiotomy has been reported to be $88.32 \%$ in Mashhad and $80 \%$ in Hamedan (8).

Complications of perineal injuries associated with childbirth are one of the most important health issues. 
Because episiotomy requires suturing, it can cause complications such as pain, bleeding, and infection during intercourse and, in the long term, urinary incontinence (9). Perineal pain is the earliest complication of episiotomy, the prevalence of which is $96.4 \%$ and $12 \%$ in the world according to the visual analogue scale of pain on the $1^{\text {st }}$ and $90^{\text {th }}$ days after delivery, respectively. $89.7 \%$ of postpartum women reported varying degrees of perineal pain, including $53 \%$ mild pain, $33 \%$ moderate pain, and $3.7 \%$ severe pain. Delayed damage to the perineum increases the severity of pain in the area (10). Perineal pain can affect the physical, mental and social aspects of women's health. It can also disrupt the process of breastfeeding, family life, and sex (11).

Therapeutic approaches to relieve perineal pain in the postpartum period include a variety of pharmacological (including oral and local anesthesia) and nonpharmacological methods such as the use of ice-cold bath/ ice packs (12).

Oak (Quercus infectoria), lavender, turmeric, Aloe vera, pineapple and marigold are currently used to reduce perineal pain due to episiotomy (8). The $21^{\text {st }}$ century is the century of return to nature; plants are being increasingly used during this century (13). There are reports of the use of herbal remedies for pain control that, despite the lack of scientific evidence, explanation of the use of these herbal remedies for pain relief has been reported. Using safe methods during breastfeeding is of benefit to women who have undergone episiotomy. The Quercus infectoria (oak tree) has greenish-gray leaves with hairy branches and oval fruits that weigh about 15 to $20 \mathrm{~g}$ and is encapsulated in a cup. The oak pair is a thin shell surrounding the main fruit and contains substantial amounts of tannins (14). Tannins are the major polyphenolic groups playing various biological and medicinal roles, including antioxidant, anticancer, anti-inflammatory, antibacterial, antimutation, and cardioprotective activities. Oak pair also has high levels of phenol and flavonoid compounds. Flavonoids have biological properties with possible therapeutic effects, such as antihepatotoxic, antitumor, antimicrobial, antioxidant, anti-allergic, anti-inflammatory, and analgesic activities. Tannins cover a wide range of biological and pharmacological activities, including antibacterial, antiinflammatory, anti-mutational, and cardioprotective properties (15). In a study conducted by Jahanshahi et al (16) on the effect of oak and lemongrass combination on the control of minor aphthous ulcers of the oral mucosa, promising results regarding the effectiveness of the plant combination were reported, with a relative improvement of $86.6 \%$ in the treated group (16). The present study was performed to investigate the effect of oak pair on episiotomy pain intensity.

\section{Materials and Methods}

This study was a double-blind clinical trial conducted from August to December 2018 to investigate the effect of oak pair cream on the severity of episiotomy pain in 120 eligible nulliparous women referred to Asali Charity Obstetrics and Gynecology Hospital, Khorramabad. After approval by the ethics committee of Shahid Beheshti School of Nursing and Midwifery in Tehran, this research project was carried out. Given 95\% confidence interval, test power $80 \%$ and average effect size 0.5 and expected correlation of 0.7 in repetition of measurements, and given 3 intervals, the minimum sample size in each group was determined to be 36 people. Given the potential dropouts, the sample size in each group was finally decided to be 40 samples. Therefore a total of 120 samples were enrolled in this study. The process of comparing the effect of oak cream, placebo, and routine care on episiotomy wound healing in nulliparous women referred to Asali Charity Hospital in Khorramabad is presented in Figure 1.

The data collection tool in this study was a personal information checklist, including demographic characteristics, midwifery, and childbirth conditions. The content validity method was used to determine the validity of this form. The developed questionnaire was distributed among 10 faculty members, obstetricians and gynecologists and, after retrieving their opinions and making final corrections, it was used. Pain intensity was also measured using a visual numerical pain scale, which is a ten-centimeter ruler and was rated from zero (painless) to 10 (maximum pain). Rahu et al reviewed the validity of this tool and considered it to be a valid tool (17). Chuang et al reviewed its reliability, and its interclass correlation reported to be 95 (18). Also, its validity and reliability have been confirmed by Kotfis et al (19).

Women fulfilling the following inclusion criteria were enrolled: nulliparous women aged 18-35 years, no drug addiction, body mass index $19.8-30\left(\mathrm{~kg} / \mathrm{m}^{2}\right)$, gestational age 37-42 weeks, living single fetus with a head display, infant weight between 4000-2500 g, vaginal delivery with medial-lateral episiotomy without other ruptures in the perineal area, delivery without assistive devices, lack of episiotomy progression to grade 3 and 4 rupture, no pregnancy complications (preeclampsia and gestational diabetes), no rupture of the bladder for more than 24 hours, no severe anemia (hemoglobin less than 7), no current or history of diseases that interfere with wound healing, no use of drugs effective in wound healing such as corticosteroids administered during the study period, no history of allergy to herbal medicines, no financial problems, and family conflicts.

Exclusion criteria included lack of referral on appointed days, no use of creams regularly and according to instructions, having an allergic reaction to oak cream, hospitalization of the infant during the study, the need to repair the perineal area, severe bleeding in the first 24 hours postpartum, fever and postpartum infection, severe postpartum constipation, or having sex in the first 10 days after delivery.

After obtaining permission from the hospital officials 


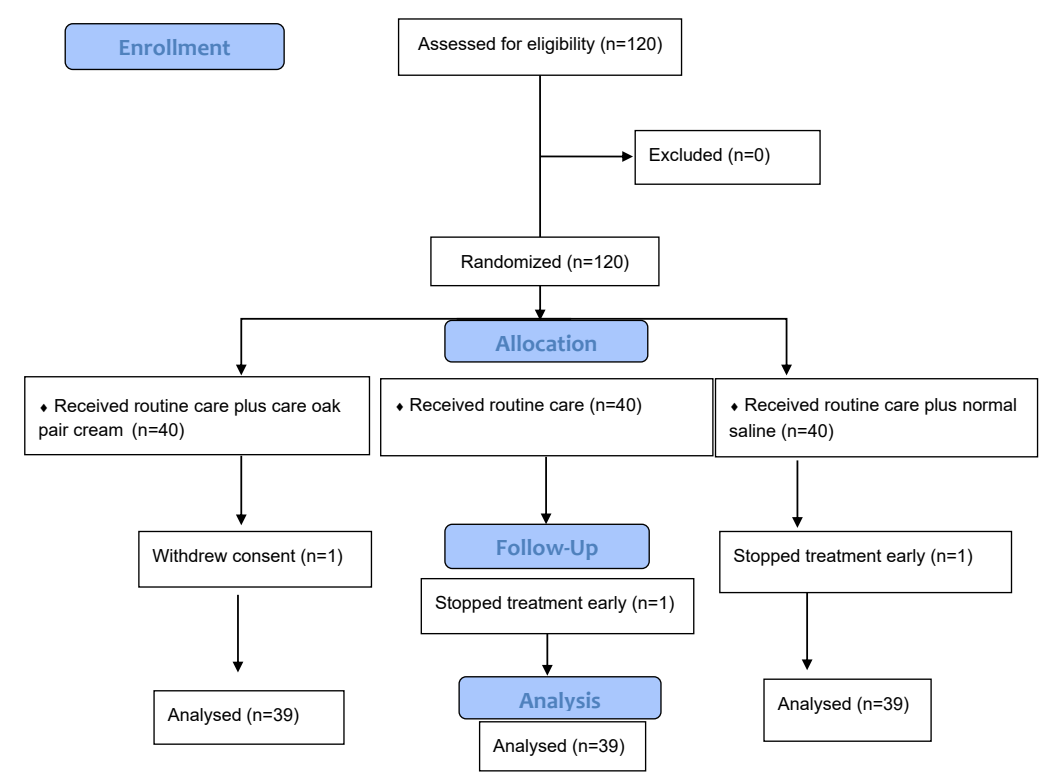

Figure 1. The process of sampling and comparing the effect of oak cream, placebo and routine care on episiotomy wound healing in nulliparous women referred to Asali Charity Hospital in Khorramabad.

and obtaining informed written consent from the sample of research units, if they fulfilled the inclusion criteria, after filling out the relevant questionnaires, entered the study and then were assigned to the studied groups using random blocks. All samples were similar in terms of episiotomy (middle-lateral), wound healing method, and the type of suture used. Health and nutritional recommendations and how to use normal saline were given to all three groups. For the convenience of research samples, an irrigator (for easy washing with normal saline serum) was provided to each sample. In the groups that received the drug code $\mathrm{A}$ or $\mathrm{B}$, the method of applying the cream was taught face to face. The participants were asked to wash the perineal area with normal saline and clean the area, apply the cream in a $2 \mathrm{~cm}$ length twice a day for 10 days at the episiotomy site, and after 2 minutes, use a clean sanitary pad.

To prepare oak pair cream, after being purchased from a medicinal plants market in Khorramabad and identified and approved by the pharmacist, the oak pairs were pulverized with an electric mill and extracted with methanol (macerationx3). The resulting extract was concentrated, and after removing the solvent, the resulting extract was mixed with $2 \%$ of the cream base and filled in $60 \mathrm{~g}$ tubes in a sterile manner. The placebo was filled with the base cream without any drug in $60 \mathrm{~g}$ tubes, the same as the drug and was given to the researcher in coded form (A and B) without any information, and the samples were completely blind of which group they belonged to. Only the pharmacist knew about the contents of the creams. All three treatment groups received routine hospital treatments, including cephalexin $500 \mathrm{mg}$ every 6 hours and mefenamic acid $250 \mathrm{mg}$ every 8 hours (if needed).
Before the intervention, all three groups underwent a baseline assessment of the pain intensity of the episiotomy site, and subsequent follow-ups were performed 24 hours after delivery on days 5 and 10 (for those who referred to a gynecologist for postpartum care).

After collecting the data and entering them in SPSS statistical software (version 21), the results of qualitative data were reported as number (percentage) and qualitative data as mean \pm standard deviation. The chi-square test was used to analyze the data if qualitative variables were compared between the groups, and the Kruskal-Wallis test was used to compare rank variables and quantitative data for which the assumption of normality was not true. Oneway analysis of variance was used to compare the means between groups. In order to compare the changes in mean pain intensity at different times within groups and between groups, a repeated measures analysis of variance (ANOVA) test was used. The probability value ( $P$ value) less than 0.05 was considered significant.

\section{Results}

This study was performed on 120 nulliparous women in Asali Hospital in Khorramabad. Three persons were excluded due to non-referral (One in each group). Finally, the data of 117 enrolled people were analyzed.

Three groups of this study were evaluated in terms of demographic characteristics, including age, body mass index, education, occupation (Table 1), as well as delivery information, including baby weight, around the baby's head, length of first, second, and third stages of delivery, use of painkillers, episiotomy size, and episiotomy repair time (Table 2). None of the parameters was statistically significant between groups. 
Table 1. Frequency distribution of research units according to personal characteristics and midwifery information

\begin{tabular}{|c|c|c|c|c|c|c|}
\hline Variables & Levels & $\begin{array}{c}\text { Normal saline group } \\
\text { No. (\%) }\end{array}$ & $\begin{array}{l}\text { Placebo group } \\
\text { No. (\%) }\end{array}$ & $\begin{array}{c}\text { Oak pair group } \\
\text { No. (\%) }\end{array}$ & Statistical test & $P$ value \\
\hline \multirow{4}{*}{$\begin{array}{l}\text { Mother's } \\
\text { education }\end{array}$} & Primary & 11 (37.9\%) & $8(27.6 \%)$ & $10(34.5 \%)$ & \multirow{4}{*}{ Chi-square } & \multirow{4}{*}{0.72} \\
\hline & Intermediate & 13 (35.1\%) & $14(37.8 \%)$ & $10(27 \%)$ & & \\
\hline & High school & $14(29.2 \%)$ & $16(33.3 \%)$ & $18(37.5 \%)$ & & \\
\hline & College & $0(0 \%)$ & $1(23.3 \%)$ & 2 (66.7\%) & & \\
\hline \multirow{4}{*}{$\begin{array}{l}\text { Spouse } \\
\text { education }\end{array}$} & Primary & 7 (35\%) & $5(25 \%)$ & $8(40 \%)$ & \multirow{4}{*}{ Chi-square } & \multirow{4}{*}{0.74} \\
\hline & Intermediate & 15 (34.9\%) & $14(32.6 \%)$ & $14(32.6 \%)$ & & \\
\hline & High school & 15 (29.4\%) & 20 (39.2\%) & $16(31.4 \%)$ & & \\
\hline & College & $1(33.3 \%)$ & $0(0 \%)$ & $2(66.7 \%)$ & & \\
\hline \multirow{4}{*}{ Mother's job } & Housewife & 38 (32.5\%) & $38(34.2 \%)$ & 38 (33.3\%) & \multirow{4}{*}{ Chi-square } & \multirow{4}{*}{0.42} \\
\hline & Manual worker & $0(0 \%)$ & $0(0 \%)$ & $0(0 \%)$ & & \\
\hline & Employee & $0(0 \%)$ & $0(0 \%)$ & $1(100 \%)$ & & \\
\hline & Free & $0(0 \%)$ & $0(0 \%)$ & $1(100 \%)$ & & \\
\hline \multirow{4}{*}{ Spouse job } & Unemployed & $2(66.7 \%)$ & $1(33.3 \%)$ & $0(0 \%)$ & \multirow{4}{*}{ Chi-square } & \multirow{4}{*}{0.38} \\
\hline & Farmer-worker & $23(34.8 \%)$ & $24(36.4 \%)$ & $19(28.8 \%)$ & & \\
\hline & Employee & $0(0 \%)$ & $0(0 \%)$ & $1(100 \%)$ & & \\
\hline & Free job & $1(27.7 \%)$ & $14(29.8 \%)$ & $20(42.6 \%)$ & & \\
\hline \multirow{4}{*}{$\begin{array}{l}\text { Number of } \\
\text { household } \\
\text { members }\end{array}$} & 2 & 32 (35.6\%) & $31(34.4 \%)$ & 27 (30\%) & \multirow{4}{*}{ Kruskal-Wallis } & \multirow{4}{*}{0.23} \\
\hline & 3 & $0(0 \%)$ & $0(0 \%)$ & $1(100 \%)$ & & \\
\hline & 4 & $4(21.1 \%)$ & $6(31.6 \%)$ & $9(47.4 \%)$ & & \\
\hline & 5 & $2(28.6 \%)$ & $(28.6 \%)$ & $3(43.9 \%)$ & & \\
\hline Age $(y)^{*}$ & - & $21.76 \pm 2.70$ & $22.58 \pm 3.93$ & $21.85 \pm 3.30$ & One-way ANOVA & 0.49 \\
\hline $\mathrm{BMI}^{*}\left(\mathrm{~kg} / \mathrm{m}^{2}\right)$ & - & $25.17 \pm 2.38$ & $24.98 \pm 2.43$ & $24.77 \pm 2.15$ & One-way ANOVA & 0.68 \\
\hline \multirow{3}{*}{ Housing status } & Personal & $4(13.3 \%)$ & $1(50 \%)$ & $11(36.7 \%)$ & \multirow{3}{*}{ Chi-square } & \multirow{3}{*}{0.05} \\
\hline & Rental mortgage & $23(35.9 \%)$ & $5(21.7 \%)$ & $22(34.4 \%)$ & & \\
\hline & Live with relatives & $11(47.8 \%)$ & 19 (29.7\%) & 7 (30.4\%) & & \\
\hline \multirow{4}{*}{ Income } & $<1$ million & $2(66.7 \%)$ & $1(33.3 \%)$ & $0(0 \%)$ & \multirow{4}{*}{ Kruskal-Wallis } & \multirow{4}{*}{0.40} \\
\hline & 1-1.5 million & $14(38.9 \%)$ & $13(36.1 \%)$ & $9(25 \%)$ & & \\
\hline & 1.5-2 million & $13(22.8 \%)$ & $20(35.1 \%)$ & $24(42.1 \%)$ & & \\
\hline & >2 million & 9 (42.9\%) & $5(23.8 \%)$ & 7 (33.3\%) & & \\
\hline
\end{tabular}

* Data are shown as mean \pm SD.

Analysis of pain intensity before intervention showed no significant difference between the mean pain intensity of the three groups $(\mathrm{P}=0.20)$. However, there was a significant decrease in the mean pain intensity score of the oak pair receiving group over time $(P<0.001)$. Similarly, there was a significant decrease in the mean score of women's pain intensity over time between placebo and normal saline groups $(P<0.001)$. There was no significant difference in the pain reduction changes between the two groups receiving placebo and normal saline $(P>0.05)$. Pain intensity was assessed before the intervention and then 1 , 5, and, 10 days after delivery. There was no statistically significant difference in pain intensity scores between the three groups of oak pair, placebo, and normal saline before the intervention $(P=0.20)$. The severity of pain on days 1,5 , and 10 after the intervention showed a significant difference between the three groups $(P<0.001)$ (Table 3$)$.

\section{Discussion}

The present study, which was performed as a doubleblind clinical trial study, showed that oak pair cream was effective in reducing perineal pain on days 1,5 , and, 10 after the intervention. Inflammation is followed by any tissue damage with an unpleasant sensation of pain. There are many anti-inflammatory compounds, one of the most well-known of which is flavonoids (19). Flavonoids are able to cross the blood-brain barrier and, through mechanisms such as affecting receptors (GABA), opioids, and adrenoceptors, are able to inhibit the enzymes that contribute to inflammation and pain and produce an analgesic effect.

Flavonoids interact with cyclooxygenase to exert their analgesic and anti-inflammatory effects. These compounds can also have analgesic and anti-inflammatory effects by inhibiting the mechanism of inhibition of prostaglandin 
Table 2. Frequency distribution of research units according to the information and characteristics of the newborn, episiotomy, and other midwifery information

\begin{tabular}{|c|c|c|c|c|c|c|}
\hline Variable & Levels & Normal saline group & Placebo group & Oak pair group & Statistical test & $P$ value \\
\hline \multirow{2}{*}{ Use of painkillers } & No & $31(29.8)$ & $35(33.7)$ & $38(36.5)$ & \multirow{2}{*}{ Chi-square } & \multirow{2}{*}{0.16} \\
\hline & Yes & $7(53.8)$ & $4(30.8)$ & $2(15.4)$ & & \\
\hline Baby weight (g) & - & $3246.05 \pm 286.25$ & $3242.30 \pm 302.30$ & $3255 \pm 238.53$ & Kruskal-Wallis & 0.86 \\
\hline Around the baby's head $(\mathrm{cm})$ & - & $34.05 \pm 0.89$ & $34.16 \pm 1.23$ & $34.31 \pm 0.95$ & Kruskal-Wallis & 0.61 \\
\hline Duration of the first stage of labor (h) & - & $7.68 \pm 2.46$ & $8.43 \pm 2.54$ & $7.93 \pm 2.83$ & Kruskal-Wallis & 0.73 \\
\hline Duration of the second stage of labor (min) & - & $40.13 \pm 11.82$ & $42.69 \pm 10.68$ & $38.12 \pm 14.08$ & Kruskal-Wallis & 0.56 \\
\hline Duration of the third stage of labor ( $\mathrm{min}$ ) & - & $11.05 \pm 2.88$ & $11.15 \pm 3.52$ & $10.50 \pm 2.20$ & Kruskal-Wallis & 0.77 \\
\hline Episiotomy size $(\mathrm{cm})$ & - & $3.32 \pm 0.28$ & $3.30 \pm 0.45$ & $3.42 \pm 0.41$ & One-way ANOVA & 0.43 \\
\hline Duration of episiotomy repair (min) & - & $13.55 \pm 2.82$ & $13.46 \pm 3.06$ & $13 \pm 2.95$ & One-way ANOVA & 0.67 \\
\hline
\end{tabular}

Note: Data are shown as mean \pm Standard deviation or number (percent).

Table 3. Comparison of the mean score of episiotomy pain intensity before the intervention and 1, 5, and 10 days after the intervention within and between the groups

\begin{tabular}{|c|c|c|c|c|c|c|}
\hline \multirow[t]{2}{*}{ Groups } & $\begin{array}{l}\text { Before the } \\
\text { intervention }\end{array}$ & $\begin{array}{l}1 \text { day after } \\
\text { intervention }\end{array}$ & $\begin{array}{l}5 \text { days after } \\
\text { intervention }\end{array}$ & $\begin{array}{l}10 \text { days after } \\
\text { intervention }\end{array}$ & \multirow{2}{*}{$\begin{array}{c}P \text { value within } \\
\text { groups }\end{array}$} & \multirow{2}{*}{$\begin{array}{c}P \text { value } \\
\text { between groups } \\
\text { (time*group) }\end{array}$} \\
\hline & Mean \pm SD & Mean \pm SD & Mean \pm SD & Mean \pm SD & & \\
\hline Oak pairs & $8.22 \pm 1.34$ & $5.30 \pm 2.04$ & $3.55 \pm 2.12$ & $1.74 \pm 1.22$ & $<0.001$ & \\
\hline Placebo & $7.84 \pm 1.34$ & $6.46 \pm 1.91$ & $5.94 \pm 1.84$ & $3.41 \pm 2.06$ & $<0.001$ & $(<0.001)$ \\
\hline Normal saline & $7.52 \pm 1.75$ & $6.73 \pm 1.73$ & $6 \pm 2.16$ & $3.81 \pm 2.59$ & $<0.001$ & \\
\hline
\end{tabular}

SD: Standard deviation; $\mathrm{n}=39$ in each group.

E2 and proinflammatory cytokines such as interleukin 1B and tumor necrosis factor a (20). Another mechanism for the analgesic and anti-inflammatory effects of flavonoids is the activation of GABA and opioid receptors (20).

Antioxidant compounds such as phenols increase the size of collagen in the wound healing area and stimulate angiogenesis, proliferation, and differentiation of keratinocytes in the wound site and cause wound healing (21). Researchers also confirmed accelerating wound healing using Oak infectia species due to increased levels of antioxidant enzymes. A study showed that aqueous extract of oak pair, compared to silver sulfadiazine, healed burn wounds in male mice in a shorter time (22). In agreement with this study, the oak pairs have woundhealing properties and, therefore, might reduce pain (22).

In addition, in a study, coriander gum smoke had no significant effect on improving episiotomy pain. Coriander, like oak, contains flavonoid compounds that are expected to have analgesic effects. The reason for the difference between the results of the present study and the study of Modi et al can be attributed to the difference between the route of drug administration and the dose used in the two studies. It seems that in topical use, the drug is in contact with the affected area for a longer time and has more functional power (23). In a study aimed at evaluating the combined ointment of chamomile and marigold on the episiotomy pain intensity of nulliparous women and comparing the pain intensity before the intervention, and on days 1, 5, 10 after intervention, the mean pain intensity in the intervention group was significantly lower. This might be explained by the presence of flavonoid compounds that can improve pain by inhibiting the release of harmful histamines and enzymes. The effect of St. John's Wort cream was also studied on perineal pain after episiotomy in nulliparous women using the visual pain scale to measure pain before the intervention, 12 hours, and 5 and 10 days after delivery, which showed a significant decrease in mean pain intensity. This effect has been attributed to its biological compounds such as flavonoids and tannins $(24,25)$. The presence of these compounds in oak can be predicted by its exerting analgesic effect through a similar process. Medicinal plants due to their active ingredients and antioxidant activities have beneficial effects on human health and have a substantial role in the treatment of diseases (26-39).

\section{Conclusion}

Oak pair can affect the severity of perineal pain after episiotomy and reduce perineal pain. Since this study is the first clinical trial to investigate the effect of oak pair on pain relief, it seems that more trials with higher sample sizes are needed to arrive at a more reliable conclusion.

\section{Acknowledgments}

This article is a part of the dissertation of Shahid Beheshti University of Medical Sciences, Tehran, Iran. Hereby, 
we would like to thank the hospital administration, the staff of the delivery unit and all the participants for their cooperation.

\section{Authors' contributions}

RS and FN conceptualized the research and prepared the draft of manuscript; $\mathrm{MB}$ and FM reviewed the literature and analyzed the data; RS, FN, FM, and MB prepared the draft. All authors read and approved the final report.

\section{Conflict of interests}

The authors declare no conflict of interest.

\section{Ethical considerations}

The studies were conducted according to protocols approved by institutional ethical committee with the ethics code IR.SBMU.PHNM.1396, 849. This article is a part of the dissertation of Shahid Beheshti University of Medical Sciences, which has been registered.

\section{Funding/Support}

This study was supported by a grant from Shahid Beheshti University of Medical Sciences (IR.SBMU.PHNM.1396, 849.

\section{References}

1. Jug Došler A, Mivšek AP, Verdenik I, Škodič Zakšek T, Levec T, Petročnik P. Incidence of episiotomy in Slovenia: the story behind the numbers. Nurs Health Sci. 2017;19(3):3517. doi: $10.1111 /$ nhs. 12352.

2. Jovanovic NS, Kocijancic DM, Terzic MM. Current approach to episiotomy: inevitable or unnecessary? Open Med. 2011;6(6):685-90. doi: doi:10.2478/s11536-0110088-z.

3. Technical Working Group, World Health Organization. Care in normal birth: a practical guide. Birth. 1997;24(2):121-3.

4. Frankman EA, Wang L, Bunker $\mathrm{CH}$, Lowder JL. Episiotomy in the United States: has anything changed? Am J Obstet Gynecol. 2009;200(5):573.e1-7. doi: 10.1016/j. ajog.2008.11.022.

5. El-Saidy TM, Aboushady RM, Soliman HF. Effect of applying crushed ice gel pads on episiotomy pain and wound healing among postpartum primiparous women. International Journal of Nursing Didactics. 2018;8(7):1929. doi: 10.15520/ijnd.v8i07.2223.

6. Ho JJ, Pattanittum P, Japaraj RP, Turner T, Swadpanich $\mathrm{U}$, Crowther CA. Influence of training in the use and generation of evidence on episiotomy practice and perineal trauma. Int J Gynaecol Obstet. 2010;111(1):13-8. doi: 10.1016/j.ijgo.2010.04.035.

7. Zaidan A, Hindi M, Bishara A, Alolayan S, Abduljabbar H. The awareness regarding the episiotomy procedure among women in Saudi Arabia. Mater Sociomed. 2018;30(3):1937. doi: $10.5455 / \mathrm{msm} .2018 .30 .193-197$.

8. Masoumi Z, Keramat A, Hajiaghaee R. Systematic review on effect of herbal medicine on pain after perineal episiotomy and cesarean cutting. J Med Plants. 2011;10(40):1-16. [Persian].
9. Jiang H, Qian X, Carroli G, Garner P. Selective versus routine use of episiotomy for vaginal birth. Cochrane Database Syst Rev. 2017;2(2):CD000081. doi: 10.1002/14651858. CD000081.pub3.

10. Malekpour P, Sehatie F. The effect of turmeric solution on pain intensity on episiotomy in primiparous women. Int J Gynecol Obst. 2009;107(4).

11. Frohlich J, Kettle C. Perineal care. BMJ Clin Evid. 2015;2015:1401.

12. Leventhal LC, de Oliveira SM, Nobre MR, da Silva FM. Perineal analgesia with an ice pack after spontaneous vaginal birth: a randomized controlled trial. J Midwifery Womens Health. 2011;56(2):141-6. doi: 10.1111/j.15422011.2010.00018.x.

13. Samsam Shariat H. Selection of Medicinal Plants. Isfahan: ManiS; 2007. p. 1-154.

14. Khosravi AD, Behzadi A. Evaluation of the antibacterial activity of the seed hull of Quercus brantii on some gram negative bacteria. Pak J Med Sci. 2006;22(4):429-32.

15. Kumari M, Jain S. Tannins: an antinutrient with positive effect to manage diabetes. Res J Recent Sci. 2012;1(12):7073.

16. Jahanshahi GR, Moatar F, Soltani MR. Evaluation of a herbal medicine in the treatment of recurrent aphthous ulcer. Shahid Beheshti Univ Med Sci. 2003;22(1):19-25. [Persian].

17. Rahu MA, Grap MJ, Ferguson P, Joseph P, Sherman S, Elswick RK Jr. Validity and sensitivity of 6 pain scales in critically ill, intubated adults. Am J Crit Care. 2015;24(6):514-23. doi: 10.4037/ajcc2015832.

18. Chuang LL, Lin KC, Hsu AL, Wu CY, Chang KC, Li YC, et al. Reliability and validity of a vertical numerical rating scale supplemented with a faces rating scale in measuring fatigue after stroke. Health Qual Life Outcomes. 2015;13:91. doi: 10.1186/s12955-015-0290-9.

19. Kotfis K, Zegan-Barańska M, Szydłowski Ł, Żukowski M, Ely EW. Methods of pain assessment in adult intensive care unit patients - Polish version of the CPOT (Critical Care Pain Observation Tool) and BPS (Behavioral Pain Scale). Anaesthesiol Intensive Ther. 2017;49(1):66-72. doi: 10.5603/ait.2017.0010.

20. Mansourabadi AH, Sadeghi HM, Razavi N, Rezvani E. Anti-inflammatory and analgesic properties of Salvigenin, Salvia officinalis flavonoid extracted. Adv Herb Med. 2016;2(1):31-41.

21. Zahedi P, Rezaeian I, Ranaei-Siadat SO, Jafari SH, Supaphol P. A review on wound dressings with an emphasis on electrospun nanofibrous polymeric bandages. Polym Adv Technol. 2010;21(2):77-95. doi: 10.1002/pat.1625.

22. Hajhashemi V, Sadraei H, Ghannadi AR, Mohseni M. Antispasmodic and anti-diarrhoeal effect of Satureja hortensis L. essential oil. J Ethnopharmacol. 2000;71(12):187-92. doi: 10.1016/s0378-8741(99)00209-3.

23. Hart CE, Loewen-Rodriguez A, Lessem J. Dermagraft: use in the treatment of chronic wounds. Adv Wound Care (New Rochelle). 2012;1(3):138-41. doi: 10.1089/ wound.2011.0282.

24. Moudi Z, Edozahi M, Emami SA, Asili J, Shahraki Pour M. Effects of mastic oleoresin on wound healing and episiotomy pain: a mixed methods study. J Ethnopharmacol. 
2018;214:225-31. doi: 10.1016/j.jep.2017.12.028.

25. Verri WA, Vicentini FTMC, Baracat MM, Georgetti SR, Cardoso RDR, Cunha TM, et al. Flavonoids as antiinflammatory and analgesic drugs: mechanisms of action and perspectives in the development of pharmaceutical forms. In: Atta ur R, ed. Studies in Natural Products Chemistry. Vol 36. Elsevier; 2012. p. 297-330. doi: 10.1016/ b978-0-444-53836-9.00026-8.

26. Wirth JH, Hudgins JC, Paice JA. Use of herbal therapies to relieve pain: a review of efficacy and adverse effects. Pain Manag Nurs. 2005;6(4):145-67. doi: 10.1016/j. pmn.2005.08.003.

27. Moayeri A, Azimi M, Karimi E, Aidy A, Abbasi N. Attenuation of morphine withdrawal syndrome by Prosopis farcta extract and its bioactive component luteolin in comparison with clonidine in rats. Med Sci Monit Basic Res. 2018;24:151-8. doi: 10.12659/msmbr.909930.

28. Bahmani M, Mozaffari Nejad AS, Shah NA, Shah SA, Rafieian-Kopaei M, Mahmoodnia L. Survey on ethnobotanical uses of anti-cancer herbs in Southern region of Ilam, West Iran. J Biol Res. 2017;90(1):5939. doi: 10.4081/jbr.2017.5939.

29. Abbasi N, Khosravi A, Aidy A, Shafiei M. Biphasic response to luteolin in MG-63 osteoblast-like cells under high glucose-induced oxidative stress. Iran J Med Sci. 2016;41(2):118-25.

30. Bahmani $M$, Taherikalani $M$, Khaksarian M, RafieianKopaei M, Ashrafi B, Nazer M, et al. The synergistic effect of hydroalcoholic extracts of Origanum vulgare, Hypericum perforatum and their active components carvacrol and hypericin against Staphylococcus aureus. Future Sci OA. 2019;5(3):FSO371. doi: 10.4155/fsoa-2018-0096.

31. Abassi N, Ghaneialvar H, Shahsavari S. Natural remedies effective on stomachache in traditional medicine. Plant Biotechnol Persa. 2020;2(1):42-7. doi: 10.29252/pbp.2.1.42.

32. Abbaszadeh S, Andevari AN, Koohpayeh A, Naghdi $\mathrm{N}$, Alizadeh M, Beyranvand F, et al. Folklore medicinal plants used in liver disease: a review. Int J Green Pharm. 2018;12(3):S463-72.
33. Zangeneh $\mathrm{MM}$, Ghaneialvar $\mathrm{H}$, Akbaribazm $\mathrm{M}$, Ghanimatdan M, Abbasi N, Goorani S, et al. Novel synthesis of Falcaria vulgaris leaf extract conjugated copper nanoparticles with potent cytotoxicity, antioxidant, antifungal, antibacterial, and cutaneous wound healing activities under in vitro and in vivo condition. J Photochem Photobiol B. 2019;197:111556. doi: 10.1016/j. jphotobiol.2019.111556.

34. Sedighi M, Sewell RDE, Nazari A, Abbaszadeh S, Cheraghi $\mathrm{M}$, Amini A, et al. A review on the most important medicinal plants effective in cardiac ischemia-reperfusion injury. Curr Pharm Des. 2019;25(3):352-8. doi: 10.2174/13 81612825666190329144016.

35. Eftekhari Z. Antimicrobial properties of medicinal plants; the new therapeutic aspect of Valeriana officinalis. Plant Biotechnol Persa. 2020;2(1):59-60. doi: 10.29252/ pbp.2.1.59.

36. Mahdavi B, Saneei S, Qorbani M, Zhaleh M, Zangeneh A, Zangeneh MM, et al. Ziziphora clinopodioides Lam leaves aqueous extract mediated synthesis of zinc nanoparticles and their antibacterial, antifungal, cytotoxicity, antioxidant, and cutaneous wound healing properties under in vitro and in vivo conditions. Appl Organomet Chem. 2019;33(11):e5164. doi: 10.1002/aoc.5164.

37. Magbool FF, Ibrahim Elnima EM, Shayoub ME, Hamedelniel EI, Mahmoud Gamil A, Adam ME, et al. Formulation design, development and evaluation of Quercus infectoria galls extract oral gels. Plant Biotechnol Persa. 2020;2(2):1-13.

38. Nouri A, Heidarian E, Amini-Khoei H, Abbaszadeh S, Basati G. Quercetin through mitigation of inflammatory response and oxidative stress exerts protective effects in rat model of diclofenac-induced liver toxicity. J Pharm Pharmacogn Res. 2019;7(3):200-12.

39. Valadi A, Nasri S, Abbasi N, Amin G. Antinociceptive and anti-inflammatory effects of hydroalchoholic extract of Anethum graveolens L. seed. J Med Plants. 2010;9(34):12430. [Persian]. 